\title{
IMPAIRED TRIGLYCERIDE TOLERANCE IN HEMODIALYSIS PATIENTS WITH DIFFERENT APOLIPOPROTEIN E (APO E) ISOFORMS
}

\author{
Jana Zahálkováa ${ }^{*}$, Helena Vaverkováa ${ }^{a}$ Dalibor Novotnýb, Zdena Kosatíkováa \\ a* $3^{\text {rd }}$ Clinic of Internal Medicine, University Hospital Olomouc, I.P.Pavlova 6, 77520 Olomouc, Czech Republic, \\ e-mail: jana.zahalkova@fnol.cz \\ ${ }^{b}$ Department of Clinical Chemistry, University Hospital Olomouc
}

Received: September 20, 2002

Key words: Uremic dyslipidemia / Apolipoprotein E / Apo E isoforms / Postprandial lipid metabolism

The influence of apolipoprotein E isoforms on fasting and postprandial lipid levels on Olomouc hemodialysis patients with uremic dyslipidemia is presented in this article.

\section{INTRODUCTION}

Uremic dyslipidemia is an important risk factor for accelerated atherosclerosis, contributing to the many times higher cardiovascular mortality of hemodialysis (HD) patients (pts) in comparison to nonuremic population ${ }^{1}$.

The influence of genetic determinants in this disorder has been widely studied, including apo E genetic variation and its relationship to cardiac and cerebrovascular disease. Owing to different affinities of apo $\mathrm{E}$ isoforms for apo $\mathrm{B} / \mathrm{E}$ and apo $\mathrm{E}$ receptors, apo $\mathrm{E}$ polymorphism has an impact on lipid metabolism and lipid plasma levels ${ }^{2,3}$.

\section{MATERIALS AND METHODS}

We performed apo E genotyping using PCR amplification and restriction-enzyme digestion RFLP in 87 uremic pts on chronic hemodialysis, 53 males and 34 females, of mean age $57.50 \pm 14.10$ years ${ }^{4}$. We followed up relative frequency of common alleles and apo $\mathrm{E}$ genotypes in HD pts, in a control group of healthy people and in a random sample of the Czech population (MONIKA).
We compared the influence of E2, E3, E4 alleles and main genotypes E3/3, 2/3, 3/4 on fasting lipid levels: apolipoproteins A1, B (apoA1, apoB), triglycerides (TG), total cholesterol (TC), HDL cholesterol (HDL-C) and LDL cholesterol (LDL-C).

Than we investigated postprandial lipid metabolism in 23 dialyzed and 11 healthy men after a standard fat load per $\mathrm{m} 2$ of body surface. Fatty meal contained $51.2 \mathrm{~g}$ of total fat, $195 \mathrm{mg}$ of cholesterol, $11.2 \mathrm{~g}$ of carbohydrates and $5.2 \mathrm{~g}$ of protein, which was $531 \mathrm{kcal}$ of energy. Over 10 hours, at $4^{\text {th }}, 5^{\text {th }}, 6^{\text {th }}, 8^{\text {th }}$ and $10^{\text {th }}$ hour after fatty load TG, TC, HDL-C and apo A1 were evaluated. Areas under the time-dependent concentration curves (AUC) were calculated for each parameter. The chi-square test and analysis of variance (ANOVA) were used for statistical analysis.

\section{RESULTS}

The distribution of apo $E$ genotypes and apo $E$ allelic frequency among HD pts corresponded to common Czech population (Table 1, Table 2).

Table 1. Relative frequency of common alleles of apo E gene in dialysis patients, in the control group of healthy people and in the random sample of the Czech population ( MONIKA )

\begin{tabular}{|l|c|c|c|c|}
\hline Population & Allele ( No ) & Allele E2 & Allele E3 & Allele E4 \\
\hline HD males & 106 & $8.5 \%$ & $84.0 \%$ & $7.5 \%$ \\
\hline HD females & 68 & $7.4 \%$ & $83.8 \%$ & $8.8 \%$ \\
\hline HD all & 174 & $8.1 \%$ & $83.8 \%$ & $8.1 \%$ \\
\hline Controls & 134 & $3.0 \%$ & $88.8 \%$ & $8.2 \%$ \\
\hline MONIKA & 578 & $7.6 \%$ & $81.7 \%$ & $10.9 \%$ \\
\hline
\end{tabular}


Table 2. Prevalence of apo E genotypes in dialysis patients, in the control group of healthy people and in the random sample of the Czech population (MONIKA)

\begin{tabular}{|l|c|c|c|c|c|c|c|}
\hline Population & $\mathrm{n}$ & $\mathrm{E} 2 / 2$ & $\mathrm{E} 2 / 3$ & $\mathrm{E} / 3$ & $\mathrm{E} 3 / 4$ & $\mathrm{E} 4 / 4$ & $\mathrm{E} 2 / 4$ \\
\hline HD males & 53 & $1.9 \%$ & $11.3 \%$ & $71.7 \%$ & $13.2 \%$ & $0.0 \%$ & $1.9 \%$ \\
\hline HD females & 34 & $0.0 \%$ & $8.8 \%$ & $73.5 \%$ & $11.8 \%$ & $0.0 \%$ & $5.9 \%$ \\
\hline HD all & 87 & $1.2 \%$ & $10.3 \%$ & $72.4 \%$ & $12.6 \%$ & $0.0 \%$ & $3.5 \%$ \\
\hline Controls & 67 & $0.0 \%$ & $4.5 \%$ & $80.6 \%$ & $11.9 \%$ & $1.5 \%$ & $1.5 \%$ \\
\hline MONIKA & 289 & $0.0 \%$ & $13.5 \%$ & $66.1 \%$ & $17.6 \%$ & $1.0 \%$ & $1.7 \%$ \\
\hline
\end{tabular}

Fasting lipid profile of HD pts was characterized by numerous abnormalities in comparison with healthy controls (Table 3).

Table 3. Lipid parameters ( mean $\pm \mathrm{SD}$ ) in dialysis patients in comparison with healthy controls

\begin{tabular}{|l|c|c|c|}
\hline Lipid parameters & $\begin{array}{c}\text { HD patients } \\
\mathrm{n}=60(32 \mathrm{M}, 28 \mathrm{~F})\end{array}$ & $\begin{array}{c}\text { Healthy controls } \\
\mathrm{n}=107(57 \mathrm{M}, 50 \mathrm{~F})\end{array}$ & $\mathrm{p}$ \\
\hline TC $(\mathrm{mmol} / \mathrm{l})$ & $5.17(1.58)$ & $5.07(1.21)$ & n.s. \\
\hline non HDL-C $(\mathrm{mmol} / \mathrm{l})$ & $3.94(1.44)$ & $3.65(1.39)$ & n.s. \\
\hline apo B $(\mathrm{g} / \mathrm{l})$ & $1.22(0.37)$ & $1.20(0.33)$ & n.s. \\
\hline TG $(\mathrm{mmol} / \mathrm{l})$ & $2.04(1.39)$ & $1.32(0.77)$ & 0.001 \\
\hline HDL-C $(\mathrm{mmol} / \mathrm{l})$ & $1.23(0.41)$ & $1.38(0.34)$ & 0.01 \\
\hline apo A1 $(\mathrm{g} / \mathrm{l})$ & $1.50(0.35)$ & $1.74(0.30)$ & 0.001 \\
\hline LpAI $(\mathrm{g} / \mathrm{l})$ & $0.51(0.17)$ & $0.63(0.15)$ & 0.001 \\
\hline
\end{tabular}

Apo E 2/3 uremic subjects $(n=9)$ had significantly higher fasting TG level comparing with E 3/3 $(\mathbf{n}=\mathbf{5 7})$ and $\mathbf{E} \mathbf{3} / \mathbf{4}(\mathbf{n}=\mathbf{1 1})$ patients. (Table 4$)$

Table 4. Plasma lipid values (mean $\pm \mathrm{SD}$, median) versus apo $\mathrm{E}$ genotype in dialysis patients

\begin{tabular}{|l|c|c|c|c|}
\hline Lipid values & apo E3/3 & apo E3/4 & apo E2/3 & $\mathrm{p}$ \\
\hline TG & $1.97 \pm 0.87(1.85)$ & $1.94 \pm 1.52(1.57)$ & $2.98 \pm 1.52(2.64)$ & $\begin{array}{c}\mathrm{E} 2 / 3 \mathrm{vs} \mathrm{3/3} \text { and } \\
3 / 4, \mathrm{p}<0.05\end{array}$ \\
\hline TC & $5.2 \pm 1.36(5.12)$ & $5.10 \pm 1.46(5.01)$ & $5.49 \pm 0.78(5.37)$ & n.s. \\
\hline HDL-C & $1.15 \pm 0.35(1.1)$ & $1.07 \pm 0.48(1.07)$ & $1.15 \pm 0.56(1.07)$ & n.s. \\
\hline LDL-C & $3.15 \pm 1.11(3.04)$ & $3.26 \pm 1.20(3.13)$ & $3.03 \pm 0.57(2.97)$ & n.s. \\
\hline apo A1 & $1.26 \pm 0.32(1.32)$ & $1.28 \pm 0.34(1.29)$ & $1.38 \pm 0.28(1.36)$ & n.s \\
\hline apo B & $1.08 \pm 0.32(1.03)$ & $1.21 \pm 0.29(1.20)$ & $1.28 \pm 0.68(1.02)$ & n.s. \\
\hline
\end{tabular}


Ten hours postprandial curve course of TG and HDL-C was markedly pathological in all E 3/3, E 2/3 and E 3/4 HD pts comparing with healthy controls (Fig. 1, Fig. 2, Fig. 3).

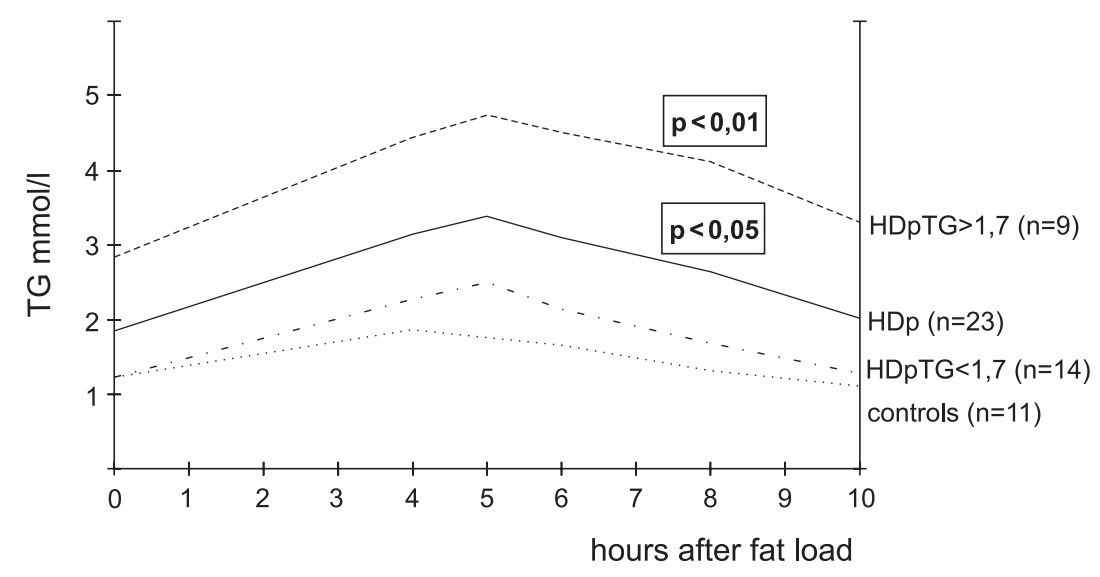

Fig. 1. Postprandial serum triglycerides in men on chronic hemodialysis

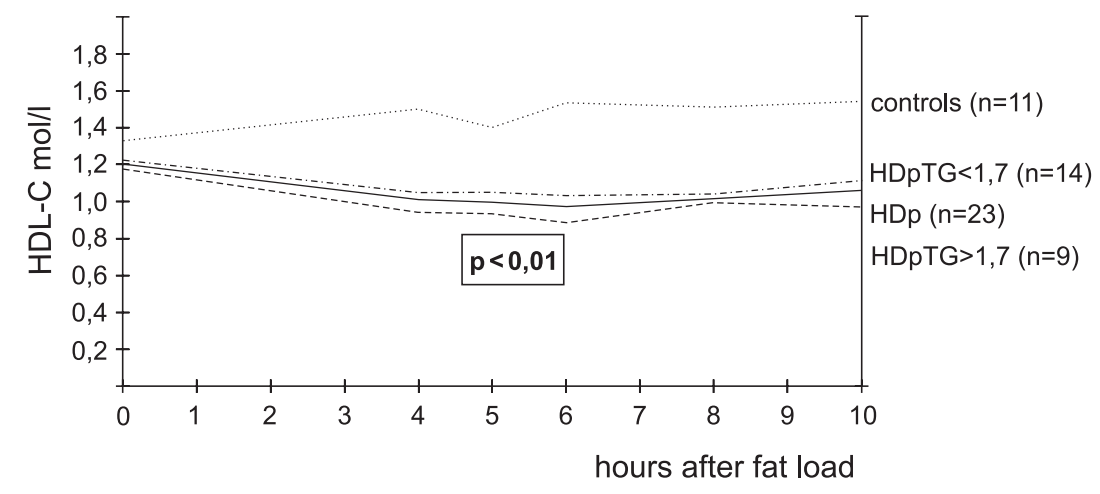

Fig. 2. Postprandial serum HDL cholesterol in men on chronic hemodialysis

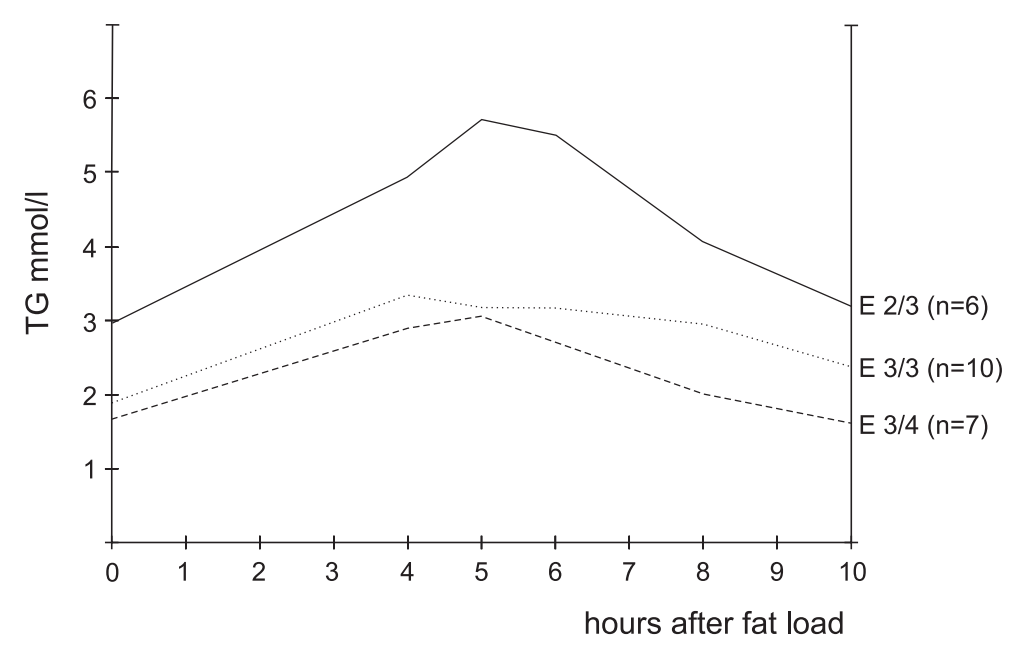

Fig. 3. Postprandial serum triglycerides in HD men in relation to apo E genotypes 
AUC-TG of E 2/3 uremic pts was significantly higher than that of $\mathrm{E} 3 / 4 \mathrm{pts}$ (Fig. 4).

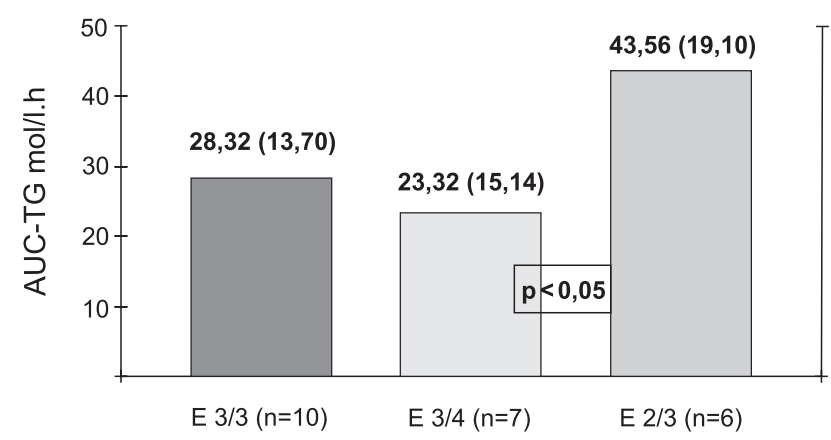

Fig. 4. Area under the time-dependent concentration curve for triglycerides in HD men. Relation to ape E genotypes.

\section{DISCUSSION}

Apo E affects the levels of all lipoproteins, either directly or indirectly by modulating their receptormediated clearance or lipolytic processing and the production of very low density hepatic lipoproteins ${ }^{5}$. Apo E2 isoforms are considered to decrease remnant clearance because of reduced affinity for the receptors, which results in the accumulation of remnant particles in plasma.

Clinical data show that not only homozygote apo E2/2 with type III HLP contributes to the development of early atherosclerosis, but apo E2/3 is a positive risk atherogenic factor too. It increases TG-rich lipoproteins and remnants and enhances macrophage cholesteryl ester syntesis when this is associated with hypertriglyceridemia ${ }^{6}$.

On the other hand the postprandial response is very heterogeneous, influenced by multiple factors, such as age, exercise, body weight, diet, fasting lipid levels and genetics too $^{7}$. Studies comparing postprandial triglyceride responses across different apo E genotypes have been done, with conflicting results.

In our group of dialysis patients ten hours postprandial TG a HDL-C levels were highly pathological in all apo E3/3, E2/3 and E3/4 pts comparing with healthy men. These changes in lipid parameters indicated a delayed degradation of the administered fatty load ${ }^{8}$. The most significant changes were evident in the subgroup of apo E2/3 uremic pts, reflecting their higher fasting TG concentration.

This abnormal postprandial lipid metabolism is of similar character observed in pts with confirmed ischemic heart disease or carotid atherosclerosis ${ }^{9,10}$ and is another manifestation of an increased atherogenic risk of HD pts.

\section{CONCLUSION}

Apo E 2/3 genotype predisposes to hypertriglyceridemia in hemodialysis patients that is followed by impaired postprandial triglyceride tolerance. This could lead to an increased atherogenic potential of uremic dyslipidemia.

\section{REFERENCES}

1. Raine AEG, Margreiter R, Brunner FP (1992) Report on Management of Renal Failure in Europe, XXII, 1991. Nephrol Dial Transplant 2, Suppl, 7-S35.

2. Wilson PWF, Myers RH, Larson M (1994) Apolipoprotein E Alleles, Dyslipidemia and Coronary Heart Disease JAMA 272, 1666-1671.

3. Dallongeville J, Lussier-Cacan S, Davignon J (1992) Modulation of plasma triglyceride levels by apoE phenotype: a meta-analysis Journal of Lipid Research 33, 447-454.

4. Bolla MK, Haddad L, Humphries SE (1995) High-throughput method for determination apolipoprotein $\mathrm{E}$ genotypes with use of restriction digestion analysis by microplate array diagonal gel electrophoresis Clin Chem, 41, 1599-1604.

5. Mahley RW, Huang Y (1999) Apolipoprotein E: from atherosclerosis to Alzheimercs disease and beyond Current Opinion in Lipidology 10, 207-217.

6. Saito M, Eto M, Makino I (1997) Triglyceride-rich lipoproteins from apolipoprotein $\mathrm{E} 3 / 2$ subjects with hypertriglyceridemia enhance cholesteryl ester synthesis in human macrophages Atherosclerosis $129,73-77$.

7. Ordovans JM, Schafer EJ (1999) Genes, variation of cholesterol and fat intake and serum lipids Current Opinion in Lipidology 10, $15-22$.

8. Weintraub M, Burstein A, Rassin T (1992) Severe defect in clearing postprandial chylomicron remnants in dialysis patients Kidney Int 42, 1247-1252.

9. Patsch JR, Miesenbóck G, Hopferwieser T (1992) Relation of triglyceride metabolism and coronary artery disease. Studies in the postprandial state Arterioscler Thromb 12, 1336-1345.

10. Ryu JE, Howard G, Craven TE (1992) Postprandial triglyceridemia and carotid atherosclerosis in middle-aged subjects Stroke 23, 823-828. 